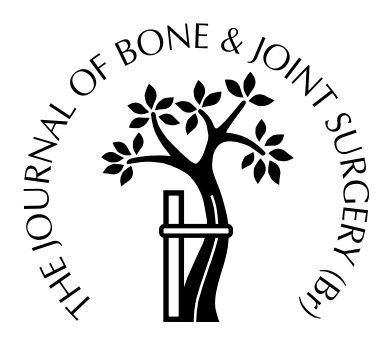

\title{
Use of hydroxyapatite to fill cavities after excision of benign bone tumours
}

\author{
CLINICAL RESULTS
}

T. Yamamoto, T Onga, T. Marui, K. Mizuno

From Kobe University School of Medicine, Japan

W e treated 75 patients with benign bone tumours by curettage and filling the defect with calcium hydroxyapatite (HA). There were 28 women and 47 men with a mean age of 27.7 years ( 3 to 80$)$. The mean follow-up was for $\mathbf{4 1 . 3}$ months. Postoperative radiological assessment revealed that the implanted HA was well incorporated into the surrounding host bone in all patients. Two patients suffered fractures in the postoperative period. Two patients complained of pain associated with $\mathrm{HA}$ in the soft tissues, but this diminished within six months. No patient had local pain at the final follow-up. Recurrence of the tumour was seen in three cases. Histopathological study of the implanted area showed removal of the HA by histiocytes and multinucleated giant cells, and the formation of much appositional bone. We conclude that $\mathrm{HA}$ is an excellent bone-graft substitute in surgery for benign bone tumours.

J Bone Joint Surg [Br] 2000;82-B:1117-20.

Received 27 March 2000; Accepted after revision 14 June 2000

Much of the basic research on calcium hydroxyapatite (HA) has concerned its clinical use as a bone-graft substitute. Biological, $^{1,2}$ histological $^{3-12}$ and biomechanical surveys of its implantation into bone ${ }^{13-15}$ reveal that the material is safe and has excellent osteoconductive properties. It is often used as a coating for prostheses as well as to fill bone defects. ${ }^{16-18}$ There have, however, been few reports on the outcome of its clinical use in surgery for bone tumours. ${ }^{19,20}$ Since 1988, we have implanted HA for bone defects after resection of benign bone tumours.

\section{Patients and Methods}

We analysed the outcome in 75 patients with benign bone tumours. There were 28 women and 47 men, with a mean

T. Yamamoto, MD, PhD, Associate Professor

T Onga, MD, Resident

T. Marui, MD, PhD, Assistant Professor

K. Mizuno, MD, Director

Department of Orthopaedic Surgery, Kobe University School of Medicine, Kobe 650-0017, Japan.

Correspondence should be sent to Dr T. Yamamoto.

(C)2000 British Editorial Society of Bone and Joint Surgery

0301-620X/00/811194\$2.00

VOL. 82-B, No. 8, NOVEMBER 2000 age of 27.7 years ( 3 to 80 ). All the lesions were imaged by plain radiography, $\mathrm{CT}$ and MRI. All patients had curettage of the tumour and filling of the resulting bone defect with HA, without autologous bone. Cortical fenestration was carried out using an osteotome and the intraosseous tumours were removed by a curette. When sclerotic margins were present they were drilled to establish a connection to healthy bone marrow. After filling the bone defect with HA, the cortical window was replaced. No other adjuvant treatment such as phenol or cryotherapy was used after curettage. Internal fixation was not employed. External stabilisation with splints or slings was utilised postoperatively for patients judged to be at risk of pathological fracture.

The tumours were located in the femur (26 patients), phalanx or metacarpal (18), tibia (11), humerus (9), calcaneus (4), pelvis (3), radius or ulna (3) and fibula (1). Histological examination revealed that 21 were enchondromas, 18 fibrous dysplasias, 12 non-ossifying fibromas, eight solitary bone cysts, six Langerhans-cell histiocytomas, three chondroblastomas, two giant-cell tumours of bone, one aneurysmal bone cyst, one intraosseous haemangioma, one osteofibrous dysplasia, one osteoid osteoma and one enostosis (bone island).

We used an HA compound $\left(\left[\mathrm{Ca}_{10}\left(\mathrm{PO}_{4}\right)_{6}(\mathrm{OH})_{2}\right]\right)$ with tricalcium phosphate (TCP) in a ratio of $70 \%$ HA to $30 \%$ TCP (Chugai Inc, Tokyo, Japan). The porosity was $3 \%$ to $55 \%$ and the pore size 1 to $15 \mu \mathrm{m}$. The sintering temperature ranged from $900^{\circ}$ to $1300^{\circ} \mathrm{C}$, and the bending strength from 50 to $800 \mathrm{~kg} / \mathrm{cm}^{2}$. Variously shaped pieces of HA were used in the operations, depending on the location and size of the tumour. The mass of implanted HA ranged from 3 to $55 \mathrm{~g}$. After surgery radiographs were assessed according to the criteria of Uchida et al $^{19}$ to determine changes in the radiolucent zone around the HA and the amount of incorporation and displacement of HA. Postoperative CT was carried out on some patients. The mean follow-up was 41 months (5 to 140).

Of the 30 patients with lesions of the upper limb, 24 were immobilised in a sling or a splint. All 18 patients with lesions in the phalanges and metacarpals had splints. The mean period of immobilisation was 3.5 weeks. Of the 42 patients with lesions in the lower limb, six were immobilised in splints. The mean period of immobilisation was 3.1 weeks. 


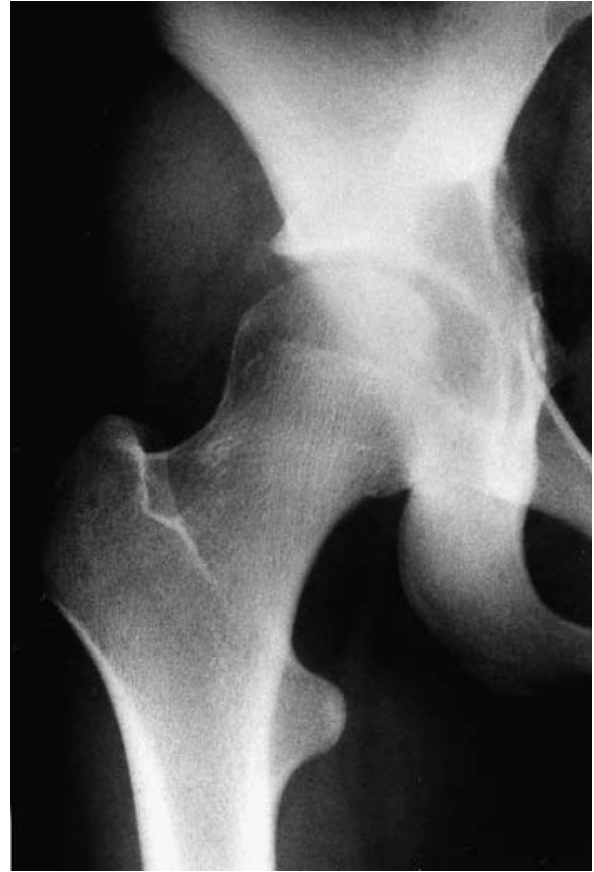

Fig. 1a

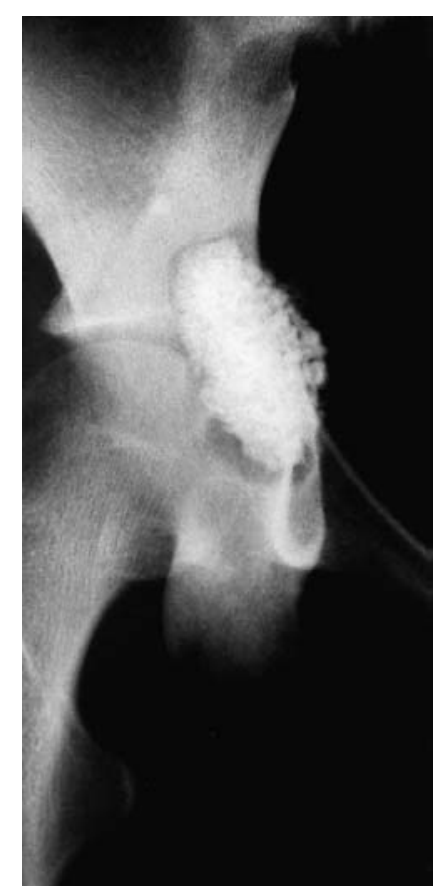

Fig. 1b

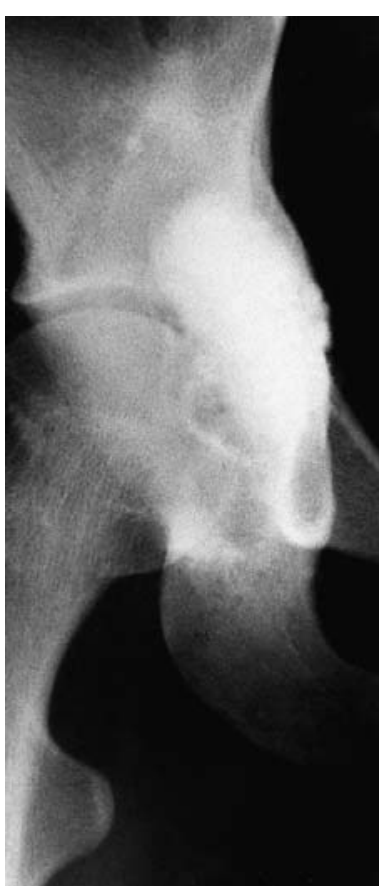

Fig. 1c

Radiographs of a 14-year-old girl with a chondroblastoma in the right acetabulum showing a) an anteroposterior view of the right hip with extensive osteolysis in the acetabulum, b) immediately after surgery with the HA implanted and surrounding radiolucent zones, and c) eight years later with homogeneously incorporated HA and remodelled bone. The joint space is preserved. There was no recurrence of the tumour.

\section{Results}

No patient developed a postoperative infection. At the final follow-up, radiography showed the implanted HA to be well incorporated into the surrounding host bone in all cases. Radiographs obtained immediately after surgery showed radiolucent zones between the implanted HA and the surrounding cancellous bone. Periodic assessments revealed that, over time, the radiolucent zones disappeared and new bone developed (Figs 1 and 2). The mean period required for the zones to disappear was 4.2 months. For patients aged 19 years or under, it was 3.2 months. As the radiolucent areas faded, radiographs showed increasing density of the material during the postoperative months, and the margins became indistinct. At the final follow-up, no degenerative changes were observed in nearby joints, even in the three chondroblastomas and two giant-cell tumours of bone in which the HA was implanted beneath the subchondral bone. No patient complained of local pain at the final follow-up. Three patients, with lesions in their

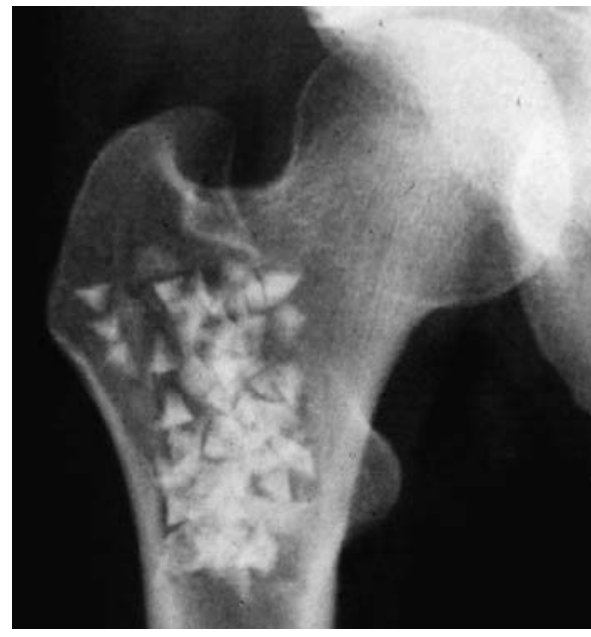

Fig. 2a

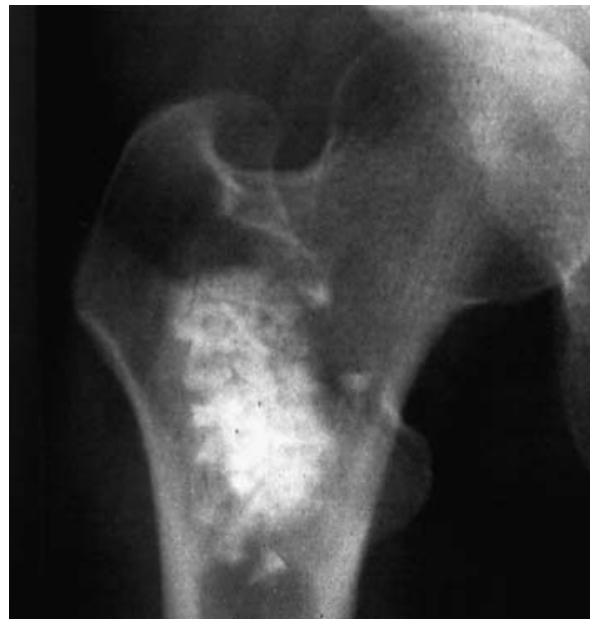

Fig. 2b
Radiographs of a 22-year-old woman with an enostosis in the right proximal femur showing a) an anteroposterior view obtained immediately after surgery, and b) nine years later with the grafted HA homogeneously incorporated, associated with indistinct margins. Sufficient bone formation was observed around the HA. 
fingers had a slightly limited range of movement in joints adjacent to the lesions. No other patient had a restricted range of movement.

For patients with a femoral or tibial lesion of larger than half of the medullary cavity as measured by CT (20 cases), the mean period before full weight-bearing was 11.3 weeks. For patients with a lesion smaller than half the medullary cavity (17 cases), the mean period required before full weight-bearing was 7.4 weeks. CT at six months or more after surgery revealed satisfactory formation of new bone around the HA.

Postoperative fractures occurred in two patients. One, with a solitary bone cyst in the humerus, fell eight days after surgery, and the other, a patient with a non-ossifying fibroma in the distal tibia, sustained a fracture while playing football two weeks after operation. Two patients with enchondromas in the fingers complained of pain attributed to particles of HA in the soft tissues. The pain decreased within six months. In one patient, with a lesion in the femur, particles of HA became displaced during rehabilitation, but had disappeared at follow-up, whereas the HA in the bone was satisfactorily incorporated.

Recurrences of tumour were seen in three cases (1 giantcell tumour of bone, 1 fibrous dysplasia and 1 Langerhanscell histiocytoma). The patient with the recurrent giant-cell tumour of bone subsequently had further curettage and packing with methylmethacrylate. The patient with recurrent fibrous dysplasia required no further surgery. The patient with a recurrent Langerhans-cell histiocytoma had an open biopsy and reimplantation of HA six months after the initial surgery. Histopathological examination showed that part of the HA implanted into the bone marrow had been replaced by histiocytes and multinucleated giant cells, but a large amount of thick, newly-formed lamellar bone was attached to the surface of the HA (Fig. 3). Infiltration of the inflammatory cells, including plasma cells and lymphocytes, was very slight.

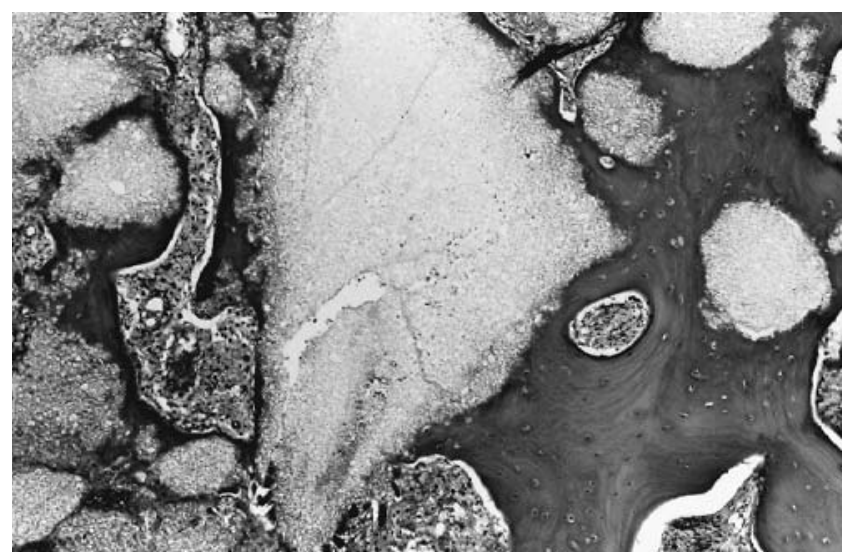

Fig. 3

Photomicrograph of a recurrent Langerhans-cell histiocytoma. The tissues were obtained from areas with recurrence of the tumour six months after the initial operation. The implanted HA was replaced by thick lamellar bone (haematoxylin and eosin $\times 70$ ).

\section{Discussion}

Since the introduction of ceramics for the replacement of bone, $^{21}$ numerous experimental and clinical studies have been undertaken. Many authors have shown bone ingrowth into HA implanted into bone marrow in animal experiments and in biopsy specimens from patients. ${ }^{3-12}$ Uchida et $^{3}$ found better bone ingrowth into HA with TCP than that with calcium aluminate. Holmes et al $^{4}$ studied HA implanted into diaphyseal defects in dogs. They observed incorporation of the HA and bone ingrowth into the material with no sign of biodegradation. Sartoris et $\mathrm{al}^{22}$ assessed the radiological changes of HA used to fill defects after fractures. They showed excellent incorporation in most cases. They demonstrated that the intrinsic architecture of the HA was preserved on radiographs, but that the margins had become indistinct, suggesting partial biodegradation of the material.

HA has various applications in orthopaedic surgery such as in bone defects resulting from severe fractures, spinal surgery and arthroplasty. Holmes et $\mathrm{al}^{5}$ applied HA while treating 18 metaphyseal and diaphyseal fractures in 1984. Uniform healing was observed in all patients. The postoperative management was similar to that after autogeneous bone grafting. In recent years, Itokazu et $\mathrm{al}^{23}$ packed HA into bone defects in fractures of the tibial plateau, and Ladd and Pliam ${ }^{24}$ used it in the treatment of distal radial fractures. It has been used in spinal fusion and laminoplasty. Bozic et $\mathrm{al}^{25}$ demonstrated that HA, used with electrical stimulation, increased the rate of lumbar spinal fusion. An HA spacer has been reported to be useful in laminoplasties. ${ }^{26}$ Many authors have reported that metal implants coated with HA achieve rapid surface bone apposition with good stability ${ }^{16-18}$ and HA has been packed into massive bone defects in revised total hip arthroplasties by Oonishi et al. ${ }^{27}$ There have been few reports in the English literature on the clinical application of HA in surgery for bone tumours.

In our series, HA was well incorporated into the surrounding host bone in all cases within a mean period of 4.2 months. The radiological changes in the implanted HA were similar to those previously reported. ${ }^{5,19,22}$ After several months, they show an increased density with indistinct margins. These radiological findings coincided with the histological evidence in a specimen obtained from the patient with recurrent Langerhans-cell histiocytoma (Fig. 3). Histological examination showed that the HA was partially removed by histiocytes and multinucleated giant cells, with the formation of appositional, thick lamellar bone. The HA had not totally disappeared in any case at final follow-up. This suggests that although HA is biodegradable, it is only very slowly replaced by new bone.

We implanted HA into the cavities of one acetabular and four epiphyseal tumours. All the lesions lay beneath the subchondral bone plate. Although follow-up was short, degenerative changes were not observed in any joint. 
Before this study, we used autologous bone grafting for tumours adjacent to joints in order to support the articular cartilage. Our results indicate that $\mathrm{HA}$ is also effective in this situation.

Postoperative fractures occurred in two patients, both within two weeks of surgery. We believe that these incidents were not directly associated with the procedure; one was accidental and the other the result of not following instructions about bearing weight. No other patient sustained a fracture after full weight-bearing had begun. Piecuch et $\mathrm{al}^{15}$ stated that once HA became incorporated, mechanical testing proved it to be as strong as normal bone. Hamson et $\mathrm{al}^{14}$ found no significant difference between HA and autologous cortical bone in mechanical strength, six months after implantation. Vuola et $\mathrm{al}^{13}$ reported that the compressive strength of HA was higher than bone marrow after 12 weeks. Full weight-bearing was, however, delayed as the radiological appearance of new bone in place of HA was slow to develop. Patients with lesions of the lower limb which were greater than half of the medullary cavity as measured by CT, required 11.3 weeks before they could safely bear full weight. The period of postoperative management is long.

Local recurrences of tumour were observed in three cases, which is similar to the recurrence rate for such tumours treated without implantation of HA and reflects the biological nature of each tumour. ${ }^{28}$

No patient complained of local pain at the final followup, but two, with enchondromas in the fingers, had pain attributed to $\mathrm{HA}$ in the soft tissues. This complication should be avoided by using a careful operative technique when packing HA into bone defects. HA in the soft tissues can be a source of mechanical irritation although only rarely does it cause a histological foreign-body reaction. ${ }^{10,11,17}$ The scattered HA disappeared within several months. It has been reported that extraskeletal implantation of HA does not lead to osteoinduction. ${ }^{29}$ We conclude that $\mathrm{HA}$ is an effective bone-graft substitute in surgery for benign bone tumours. Its implantation provides osseointegration with fewer complications and as a result we have abandoned autologous bone grafting in patients with these lesions.

No benefits in any form have been received or will be received from a commercial party related directly or indirectly to the subject of this article.

\section{References}

1. Sun JS, Lin FH, Hung TY, et al. The influence of hydroxyapatite particles on osteoclast cell activities. J Biomed Mater Res 1999;45:311-21.

2. Wilke A, Orth J, Lomb $\mathbf{M}$, et al. Biocompatibility analysis of different biomaterials in human bone marrow cell cultures. J Biomed Mater Res 1998;40:301-6.

3. Uchida A, Nade SML, McCartney ER, Ching W. The use of ceramics for bone replacement: a comparative study of three different porous ceramics. J Bone Joint Surg [Br] 1984;66-B:269-75.

4. Holmes RE, Bucholz RW, Mooney V. Porous hydroxyapatite as a bone graft substitute in diaphyseal defects: a histometric study. $J$ Orthop Res 1987;5:114-121.
5. Holmes R, Mooney V, Bucholz R, Tencer A. A coralline hydroxyapatite bone graft substitute: preliminary report. Clin Orthop 1984;188:252-62.

6. Shimizu T, Zerwekh JE, Videman T, et al. Bone ingrowth into porous calcium phosphate ceramics: influence of pulsing electromagnetic field. J Orthop Res 1988;6:248-58.

7. Takaoka T, Okumara M, Ohgushi H, et al. Histological and biochemical evaluation of osteogenic response in porous hydroxyapatite coated alumina ceramics. Biomaterials 1996;17:1499-505.

8. Sempuku T, Ohgushi H, Okumura M, Tamai S. Osteogenic potential of allogeneic rat marrow cells in porous hydroxyapatite ceramics: a histological study. J Orthop Res 1996;14:907-13.

9. Buma $\mathbf{P}$, van-Loon PJ, Versleyen $\mathbf{H}$, et al. Histological and biomechanical analysis of bone and interface reactions around hydroxyapatite-coated intramedullary implants of different stiffness: a pilot study on the goat. Biomaterials 1997;18:1251-60.

10. Suominen EA, Aho AJ, Juhanoja J, Yli-Urpo A. Hydroxyapatiteglass composite as a bone substitute in large metaphyseal cavities in rabbits. Int Orthop 1995;19:167-73.

11. Overgaard S, Lind M, Glerup $\mathbf{H}$, et al. Hydroxyapatite and fluorapatite coatings for fixation of weight loaded implants. Clin Orthop 1997;336:286-96.

12. Takahashi T, Tominaga T, Watabe N, et al. Use of porous hydroxyapatite graft containing recombinant human bone morphogenetic protein-2 for cervical fusion in a caprine model. J Neurosurg 1999;90:224-30.

13. Vuola J, Taurio R, Goransson H, Asko-Seljavaara S. Compressive strength of calcium carbonate and hydroxyapatite implants after bonemarrow-induced osteogenesis. Biomaterials 1998;19:223-7.

14. Hamson KR, Toth JM, Stiehl JB, Lynch KL. Preliminary experience with a novel model assessing in vivo mechanical strength of bone grafts and substitute materials. Calcif Tissue Int 1995;57:64-8.

15. Piecuch JF, Goldberg AJ, Shastry CV, Chrzanowski RB. Compressive strength of implanted porous replamineform hydroxyapatite. J Biomed Mater Res 1984;18:39-45.

16. D'Lima DD, Walker RH, Colwell CW Jr. Omnifit-HA stem in total hip arthroplasty: a 2- to 5-year follow-up. Clin Orthop 1999;363: 163-9.

17. Tonino AJ, Thèrin M, Doyle C. Hydroxyapatite-coated femoral stems: histology and histomorphometry around five components retrieved at post mortem. J Bone Joint Surg [Br] 1999;81-B:148-54.

18. Regner L, Carlsson L, Karrholm J, Herberts P. Ceramic coating improves tibial component fixation in total knee arthroplasty. J Arthroplasty 1998;13:882-9.

19. Uchida A, Araki N, Shinto Y, et al. The use of calcium hydroxyapatite ceramic in bone tumour surgery. J Bone Joint Surg [Br] 1990;72-B:298-302.

20. Uchida A, Shinto A, Araki N, Ono K. Slow release of anticancer drugs from porous calcium hydroxyapatite ceramic. J Orthop Res 1992;10:440-5.

21. Smith L. Ceramic-plastic material as a bone substitute. Arch Surg 1963;87:653-61.

22. Sartoris DJ, Gershuni DH, Akeson WH, Holmes RE, Resnick D. Coralline hydroxyapatite bone graft substitutes: preliminary report of radiographic evaluation. Radiology 1986;159:133-7.

23. Itokazu M, Matsunaga T, Ishii M, Kusakabe H, Wyni Y. Use of arthroscopy and interporous hydroxyapatite as a bone graft substitute in tibial plateau fractures. Acta Orthop Trauma Surg 1996;115:45-8.

24. Ladd AL, Pliam B. Use of bone-graft substitutes in distal radius fractures. J Am Acad Orthop Surg 1999;7:279-90.

25. Bozic KJ, Glazer PA, Zurakowski D, et al. In vivo evaluation of coralline hydroxyapatite and direct current electrical stimulation in lumbar spinal fusion. Spine 1999;24:2127-33.

26. Hoshi K, Kurokawa T, Nakamura K, et al. Expansive cervical laminoplasties: observations on comparative changes in spinous process lengths following longitudinal laminal divisions using autogeneous bone or hydroxyapatite spacers. Spinal Cord 1996;34:725-8.

27. Oonishi H, Iwaki Y, Kin N, et al. Hydroxyapatite in revision of total hip replacements with massive acetabular defects: 4- to 10-year clinical results. J Bone Joint Surg [Br] 1997;79-B:87-92.

28. Huvos AG. Bone tumors: diagnosis, treatment and prognosis. Second ed. Philadelphia: W. B. Saunders Co, 1991:30-48:429-67;695-711.

29. Piecuch JF. Extraskeletal implantation of a porous hydroxyapatite ceramic. J Dent Res 1982;61:1458-60. 